\title{
A Qualitative and Quantitative Study on the Abrasivity of five Philippine-brand Toothpastes
}

\author{
Amiel Jozcef Avellona Subido and Angelina A. Atienza, DMD, MOH \\ College of Dentistry, University of the Philippines Manila
}

\begin{abstract}
Background. Relative Dentin Abrasivity (RDA), as set by ISO 11609, is a standardized measurement on the abrasiveness of toothpaste. There are no published RDA values for Philippine-brand toothpastes. This study evaluated the degree of abrasion of five Philippine-brand toothpastes.
\end{abstract}

Objective. To compare qualitatively and quantitatively the abrasivity of five Philippine-brand toothpastes (Brands $X$, $\mathrm{U}, \mathrm{H}, \mathrm{HN}, \mathrm{G}$ ) to two foreign-brand toothpastes Brand C (RDA 68) and Brand P (RDA 150).

Methods. Twenty-four bovine dentin samples were brushed with a slurry of each of the toothpaste using a toothbrushing machine. A profilometer, scanning electron microscope and a visual measuring scope were used to determine abrasivity through the before-and-after-brushing surface roughness.

Results. Ranked based on the difference of the means for surface roughness, before-and-after brushing, in decreasing order of abrasivity are: Brands P, X, U, H, C, HN, and G. Using Dunn's test-post hoc test for Kruskal-Wallis test at $p \leq 0.05$, we showed that the abrasivity of Brands $\mathrm{G}, \mathrm{H}$, and $\mathrm{HN}$ were not significantly different from Brand $\mathrm{C}$, and Brand $X$ was not significantly different from Brand $P$. Brand $U$ was significantly less abrasive than Brand $P$ and significantly more abrasive than Brand C.

Conclusion. Brands $\mathrm{G}, \mathrm{H}$, and $\mathrm{HN}$ can be considered as low-abrasive toothpastes, Brand $\mathrm{X}$ a high abrasive toothpaste, and with Brand $U$ was unclear as to category. Findings from qualitative data support the quantitative data.

Key Words: Dentin, toothpaste, tooth abrasion

\section{INTRODUCTION}

Toothpastes are used for cleaning tooth surfaces of debris and plaque, polishing tooth surfaces, removing stains, and serving as vehicle for therapeutic agents that can reduce dental caries and maintain a healthy gingiva. ${ }^{1}$ However, they contain abrasives that can contribute to tooth wear, dentin sensitivity, ${ }^{2}$ and cervical tooth abrasions. ${ }^{2-5}$ With exposure of cementum due to gingival recession, abrasives in toothpaste become a major causative factor in non-carious cervical lesions (NCCL). ${ }^{4-7}$ Knowledge and awareness of the abrasiveness of toothpastes may help in the prevention of cervical abrasions and dentin sensitivity.

Relative Dentin Abrasivity (RDA), as set by the International Standards Organization (ISO) $11609,{ }^{8}$ is a standardized measurement on the abrasiveness of toothpastes. The American Dental Association (ADA) recommends that

Corresponding author: Amiel Jozcef Avellona Subido College of Dentistry

University of the Philippines Manila

1546 Taft Ave, Ermita, Manila 1007

Email: aasubido@up.edu.ph the RDA values of dentifrices should not exceed 250 to be considered safe and effective. ${ }^{9}$ With proper tooth brushing, any toothpaste that has less than an RDA 251 can be used lifetime without any detrimental effect. ${ }^{10}$ The abrasiveness 
of toothpastes has been categorized into low - RDA 0-70, medium - RDA 71-100, high - RDA 101-150, and very highly abrasive - RDA 151-250. ${ }^{11}$

Studies recommend specific RDA levels depending on specific clinical conditions. An in-vitro study suggested that NCCLs are aggravated when using highly abrasive toothpaste, thus, low abrasive ones are advisable. ${ }^{12}$ There is a direct proportionality between RDA levels and tooth structure loss in eroded teeth. ${ }^{13} \mathrm{~A}$ study found that whitening toothpastes caused more dentin abrasion; ${ }^{14}$ however, there is also a counterclaim that not all toothpastes claiming to have a whitening effect are necessarily more abrasive than regular ones. ${ }^{15}$

There are no public records on the RDA values of Philippine-brand toothpastes that may serve as a guide for the dental profession and general population. Considered as Philippine-brand toothpastes are those manufactured by Filipino-owned companies and are Philippine-based. This study evaluated qualitatively and quantitatively five Philippine-brand toothpastes by comparing its abrasivity to two foreign-brand toothpastes with known RDA values.

Abrasives typically found in toothpaste, singly or in combination, include calcium carbonate, hydrated silica, sodium bicarbonate, dibasic calcium phosphate dehydrate, and hydrated alumina. ${ }^{1}$ The hardness of these abrasives can be assessed using the Mohs scale which roughly measures the relative hardness of a mineral's resistance to scratching. A harder material would generally indicate a more abrasive material. Table 1 presents the Mohs hardness value of some abrasives as well as that for enamel and dentin. ${ }^{16,17}$

Abrasivity may also depend on the particle size, shape or morphology, and concentration or distribution. ${ }^{17-21}$ Other than the abrasive system, evidence suggests the contribution of detergents used in toothpastes. It has been shown that sodium lauryl sulfate (SLS) increases the abrasivity of calcium carbonates and silica, while the reverse is said for betaine (a foaming ingredient). ${ }^{22}$ Citric acid (detergent) has been found to erode dentin in proportion to its concentration and that even $1 \%$ of it can remove inorganic dentin material in the same amount as the chelating agent ethylenediaminetetraacetic acid (EDTA). ${ }^{23}$

Table 1. Mohs hardness value of abrasives used in toothpastes and tooth structure

\begin{tabular}{lc}
\hline \multicolumn{1}{c}{ Material } & Mohs Hardness \\
\hline Sodium bicarbonate & 2.5 \\
Dicalcium phosphate dehydrate & 2.5 \\
Calcium carbonate & 3 \\
Anhydrous dicalcium phosphate & 3.5 \\
Dentin & $3-4$ \\
Hydrated silica dioxide & 5 \\
Calcium pyrophosphate & 5 \\
Enamel & 5 \\
\hline
\end{tabular}

On the other hand, titanium dioxide (colorant) may contribute to abrasion due to its high Mohs hardness value which can range from 5.5-6.5.

Methods of measuring abrasivity can be divided into qualitative and quantitative testing. Quantitative tests, such as weight loss, volume loss, and radiotracers measure abrasivity by quantifying how much structure is lost after the abrasion process. The gold standard in measuring dentifrice abrasivity is the RDA method; ${ }^{5}$ however, a major limitation is that it can only be carried out in laboratories in the USA or Switzerland. ${ }^{24}$ Quantitative tests alone, such as the RDA method and profilometry, would not suffice in understanding abrasivity, ${ }^{15}$ and qualitative tests such as light reflection and microscopy are also important. ${ }^{5}$

\section{MATERIALS AND METHODS}

\section{Study Design}

The research design was a single-blind randomized invitro experimental study. Using a simple random sampling (fish bowl technique), 24 bovine incisor teeth were matched with 7 toothpaste brands and one negative control (brushed with water only). Studies have found that bovine teeth are suitable substitute for human teeth. ${ }^{25}-27$ Based on a previous study, three teeth specimens were allocated for each toothpaste. ${ }^{21}$ The bovine teeth samples were obtained from the Padre Garcia public market in the province of Batangas. The teeth samples were extracted by a butcher from slaughtered cattle of the same species with nearly the same age (2.5-3.5 years old). Specimens with obvious defects, concave preparation, and small preparation were excluded.

\section{Toothpaste Selection}

Two foreign-brand toothpastes, Brand C (RDA 68) and Brand P (RDA 150), were used as positive controls and were compared with five Philippine-brand toothpastes: Brands $\mathrm{G}, \mathrm{H}, \mathrm{HN}, \mathrm{U}$, and $\mathrm{X}$, which are readily available in the local market. Table 2 lists the seven toothpaste brands with their corresponding abrasive systems.

Table 2. Abrasive Systems of the Seven Toothpaste Brands Used in this Study

\section{Toothpaste Brand Abrasive (Mohs hardness)}

\begin{tabular}{ll} 
Brand C (RDA 68) & Dicalcium phosphate dihydrate (2.5) \\
\hline Brand G & $\begin{array}{l}\text { Dicalcium phosphate dihydrate (2.5) } \\
\text { Hydrated silica (5) }\end{array}$ \\
\hline Brand H & $\begin{array}{l}\text { Dicalcium phosphate dihydrate (2.5) } \\
\text { Hydrated silica (5) }\end{array}$ \\
\hline Brand HN & Calcium carbonate (3) \\
\hline Brand P (RDA 150) & $\begin{array}{l}\text { Calcium carbonate (3) } \\
\text { Hydrated silica (5) }\end{array}$ \\
\hline Brand U & $\begin{array}{l}\text { Hydrated silica (5) } \\
\text { Mica (2.5-4) }\end{array}$ \\
\hline Brand X & Hydrated silica (5) \\
& Sodium bicarbonate (2.5) \\
\hline
\end{tabular}



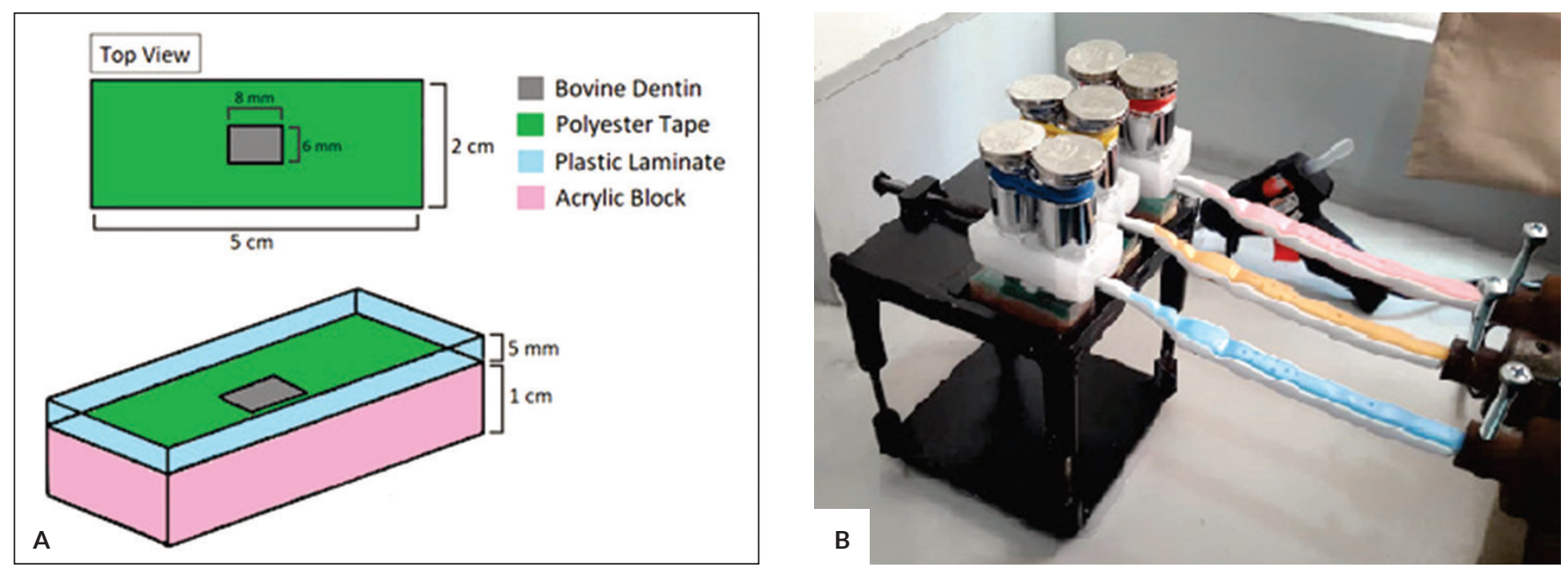

Figure 1. Illustration of the dentin block embedded on acrylic (A) and actual photo of the platform setup with cylindrical weights on toothbrushes attached to the toothbrushing machine (B).

Any test toothpaste that turns out to be equal to Brand $\mathrm{P}$ can be considered as having high abrasivity, and if more abrasive it is to be considered as very highly abrasive. With Brand C (RDA 68) as the lower positive control, any of the test toothpaste that turns out to be equal or less abrasive can be considered to have low abrasivity.

\section{Bovine Dentin Sample Preparation}

Sample preparation was done using dental burs and were polished manually using silicon carbide sandpapers to 4000 grit. A final dentin block that measures 7 by $9 \mathrm{~mm}$ were mounted on a 2 by $5 \mathrm{~cm}$ acrylic block. Polyester tape was used to cover the acrylic, creating a 6 by $8 \mathrm{~mm}$ window on the polished bovine dentin. Toothpaste slurries were freshly prepared before brushing, with a proportion of $25 \mathrm{~g}$ toothpaste per $40 \mathrm{~mL}$ water. ${ }^{28}$ The slurries were transferred to its corresponding acrylic block samples using a disposable syringe. A $5 \mathrm{~mm}$ border made of plastic laminate was attached to the side of the block to contain the slurry while brushing (Figure 1).

\section{Data Collection}

Before toothbrushing, baseline data for quantitative surface roughness using analog profilometer (Mitutoyo SJ.201P), and qualitative image scanning using a visual measuring scope (VMS iNEXIV VMA-2520) and scanning electron microscope (SEM Quanta FEG 450) were measured. The toothbrushing wear machine of the University of the Philippines College of Dentistry (UPCD) was used to brush the 24 dentin blocks. The dentin blocks were brushed with a total of 6000 strokes and a brushing rate of around 130 strokes per minute. This is equivalent to twice a day brushing for about 7 months. ${ }^{21,29}$ The 24 toothbrushes used were from one manufacturer (soft flat-trimmed bristles, regular head size, and perpendicular oriented bristles) and were mounted with 250 grams of calibrated cylindrical weights together with the casing to allow for pressure. ${ }^{15,21}$ After brushing, another set of data was collected using the profilometer, SEM, and VMS. The before-and-after data were compared to get the changes in final surface roughness. Data collection and testing were done at the UPCD Research Laboratory (toothbrushing and SEM scanning) and 3M Costumer Technical Center (profilometry testing and VMS scanning).

\section{Data Processing and Analysis}

Results were statistically analyzed using Dunn's testPost hoc test for Kruskal Wallis test (software: IBM SPSS 23) to determine if the change in surface roughness among toothpaste brands had significant differences. A significant level of $5 \%$ was chosen for all statistical tests $(p<0.05)$. Qualitative data was used to verify and supplement the quantitative data. We used the following parameters to determine whether there was an increase in surface roughness after brushing: increase in horizontal and diagonal abrasion marks (dark lines), increase in thickness of horizontal and diagonal abrasion marks, formation of horizontal band pattern of alternating dark and light shades, and deep looking areas (dark shade) that is not caused of shadow due to bad lighting. A change in at least one of the parameters should be present to conclude change in surface roughness.

\section{Ethical Consideration}

The research project was exempted from ethical review by the University of the Philippines Manila Research Ethics Board since the study did not involve human participants.

\section{RESULTS}

\section{Quantitative Findings}

We compared the mean difference in surface roughness of the dentin blocks before and after brushing between brands (Table 3). 
Table 3. Summary of the Mean Difference Before and After Toothbrushing

\begin{tabular}{lccc}
\multirow{2}{*}{ Brand } & \multicolumn{2}{c}{ Mean Surface Roughness $(\mu \mathrm{m})$} & \begin{tabular}{c} 
Difference \\
of the Means \\
\cline { 2 - 3 }$(\mu \mathrm{m})^{*}$
\end{tabular} \\
\hline $\mathrm{C}$ & 0.5633 & 0.5906 & 0.0272 \\
$\mathrm{G}$ & 0.6072 & 0.5906 & -0.0167 \\
$\mathrm{H}$ & 0.7011 & 0.7811 & 0.0800 \\
$\mathrm{HN}$ & 0.6422 & 0.6428 & 0.0006 \\
$\mathrm{P}$ & 0.5111 & 0.9083 & 0.3972 \\
$\mathrm{U}$ & 0.5394 & 0.6589 & 0.1194 \\
X & 0.6283 & 0.9783 & 0.3500 \\
Negative Control & 0.5956 & 0.5756 & -0.0200 \\
(No Toothpaste) & & & \\
\hline
\end{tabular}

Note: $A(+)$ value in the "Difference of the Means" column indicates that there was an increase in surface roughness, thus increased abrasivity; a (-) value indicates that there was a decrease in surface roughness, thus decreased abrasivity.

Table 4. Comparison of the mean difference surface roughness between two brands using Dunn's Test Post Hoc Test for Kruskal Wallis Test

\begin{tabular}{lcc} 
Brand 1 - Brand 2 & $\begin{array}{c}\text { Mean Difference in } \\
\text { Surface Roughness }\end{array}$ & $\begin{array}{c}\text { p-value } \\
\text { (two-tailed) }\end{array}$ \\
\hline C - G & 0.0439 & 0.760 \\
C - H & 0.0528 & 0.098 \\
C - HN & 0.0266 & 0.450 \\
C - P & 0.3700 & $<0.0001$ \\
C - U & 0.0922 & 0.005 \\
C - X & 0.3228 & $<0.0001$ \\
C - No Toothpaste & 0.0472 & 0.418 \\
G - H & 0.0967 & 0.050 \\
G - HN & 0.0173 & 0.653 \\
G - P & 0.4139 & $<0.0001$ \\
G - U & 0.1361 & 0.002 \\
G - X & 0.3667 & $<0.0001$ \\
G - No Toothpaste & 0.0033 & 0.614 \\
H - HN & 0.0794 & 0.016 \\
H - P & 0.3172 & $<0.0001$ \\
H - U & 0.0394 & 0.245 \\
H - X & 0.2700 & $<0.0001$ \\
H - No Toothpaste & 0.1000 & 0.014 \\
HN- P & 0.3966 & $<0.0001$ \\
HN - U & 0.1188 & $<0.0001$ \\
HN - X & 0.3494 & $<0.0001$ \\
HN - No Toothpaste & 0.0206 & 0.957 \\
P - U & 0.2778 & 0.017 \\
P - X & 0.0472 & 0.936 \\
P - No Toothpaste & 0.4172 & $<0.0001$ \\
U - X & 0.2306 & 0.014 \\
U - No Toothpaste & 0.1394 & $<0.0001$ \\
X - No Toothpaste & 0.3700 & \\
\hline
\end{tabular}

Ranked based on the difference of the means, beforeand-after brushing, in decreasing order of abrasivity: Brand $\mathrm{P}, \mathrm{X}, \mathrm{U}, \mathrm{H}, \mathrm{C}, \mathrm{HN}$, and $\mathrm{G}$.

Using the Dunn's test-Post hoc test for KruskalWallis test, compared to Brand C, Brands $\mathrm{U}$ and $\mathrm{X}$ were significantly more abrasive, while Brands $\mathrm{G}, \mathrm{H}$, and $\mathrm{HN}$ were not significantly different. Using the same test, compared to Brand P, except for Brand X, all were significantly less abrasive (Table 4).

\section{Qualitative Findings}

The SEM and the VMS were used for qualitative examination. SEM was used to be at par with existing studies $^{30,31}$ that similarly employed the machine to measure abrasivity. Any cracks, removal of the smear layer, and the exposed dentinal tubules were also readily seen. On the other hand, VMS provided a colored image with better contrast, thus, abrasion marks were better observed. Images from the SEM were generally congruent with the VMS in terms of showing signs of increase or decrease in abrasion.

Using the parameters outlined in the methodology, the VMS images were consistent with the quantitative results (Figure 2). Some samples had decreased surface roughness value, such as Brand $\mathrm{G}$ and the negative control. They showed consistent decrease in surface roughness in the images due to the absence or decrease of horizontal lines and other parameters outlined in the methodology.

\section{DISCUSSION}

Qualitative findings from VMS and SEM images were compatible with degree of abrasion from quantitative analysis. Interestingly, all the samples viewed under the SEM, showed that the dentinal tubules were more evident after brushing. This suggests that brushing even without toothpaste can remove the smear layer and expose the dentinal tubules. Likewise, using toothbrush alone did not cause significant wear to dentin as seen in the quantitative results. This finding is similar to a study which showed little difference in dentin loss after 10,000 and 20,000 brushing strokes using water alone. ${ }^{22}$

The different components in dentifrices may have an effect on abrasivity, making it difficult to conclude that the abrasive systems alone will determine the final abrasivity of a toothpaste..$^{20}$ Brand C contains only one abrasive system, dicalcium phosphate dihydrate, with a low Mohs hardness value of 2.5, which may explain its low level of abrasivity. Brand HN contains calcium carbonate with a Mohs hardness value of 3 but was found to be not significantly different from Brand C. Despite having a harder abrasive system, perhaps the presence of betaine in Brand $\mathrm{HN}$ reduced its abrasiveness, as this has been found to decrease the abrasive effect of calcium carbonate. ${ }^{22}$

Toothpastes from the same manufacturer and with the same abrasive systems can differ in their abrasivity, such 

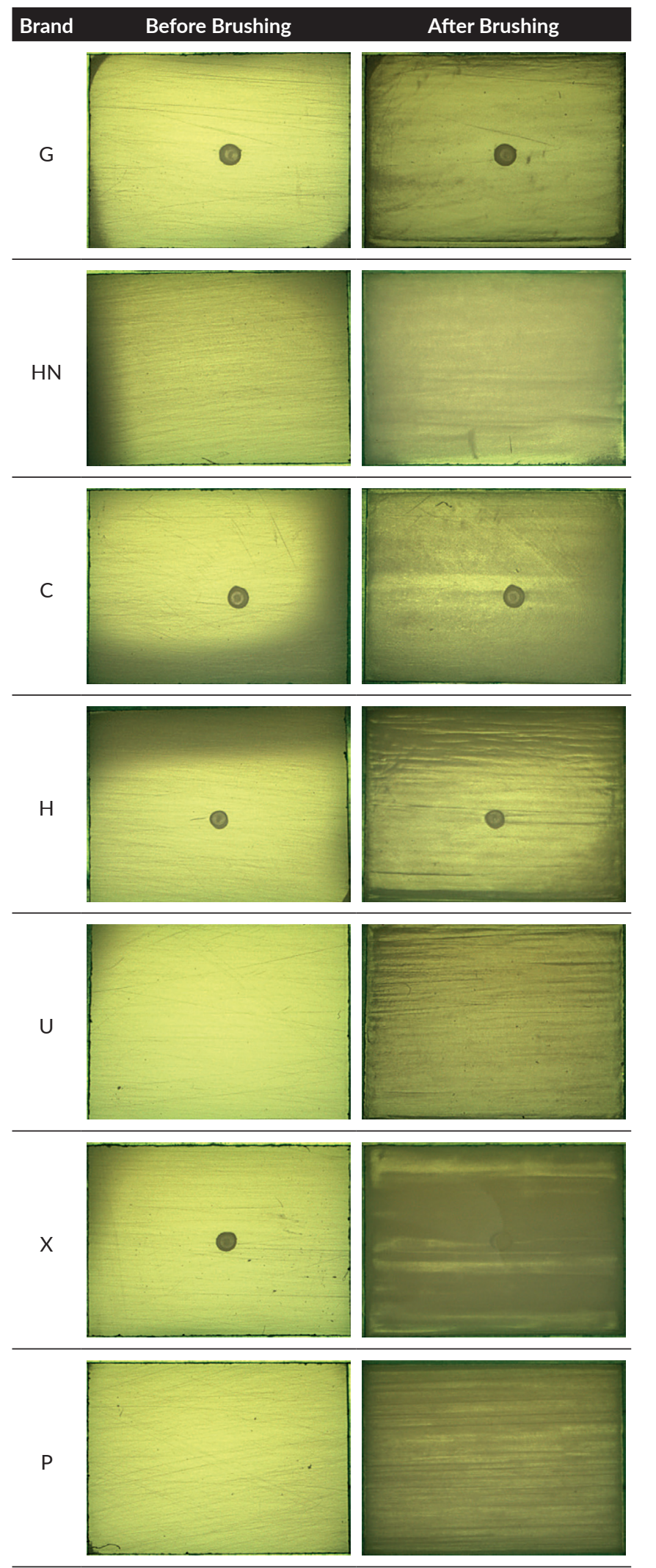

Figure 2. Samples of VMS images with $\times 120$ magnification before and after brushing of the seven toothpaste brands. as Brands $H$ and $G$ which were significantly different. If particle size, shape, types, and concentration of the abrasive systems are constant, possibly the hardness of the abrasive can be predictive of the abrasivity of a toothpaste. However, other variables may be present that may affect its overall abrasivity. Though both contain hydrated silica and dicalcium phosphate dihydrate, Brand $\mathrm{H}$ was found to be more abrasive than Brand G. Possibly contributing to Brand H's abrasivity is that it contains titanium dioxide, a colorant, with a Mohs hardness value that can range from 5.5-6.5.

Brands $\mathrm{P}, \mathrm{U}$, and $\mathrm{X}$ all contain two types of abrasives. Brand $\mathrm{P}$ has a high abrasivity possibly due to the combination of two abrasive systems - calcium carbonate and hydrated silica, with 3 and 5 Mohs hardness, respectively. Combined, these two abrasives have the highest Mohs hardness value of all the toothpastes. Brand $U$ has both hydrated silica and mica. Depending on the type of mica, its Mohs hardness can range from 2-4. Brand U may have contained the harder type of mica, which can explain why it is significantly more abrasive than Brand C.

Brand X, containing sodium bicarbonate (2.5 Mohs) and hydrated silica (5 Mohs), did not differ significantly from Brand $\mathrm{P}$, while Brand $\mathrm{G}$, containing dicalcium phosphate dihydrate (2.5 Mohs) and hydrated silica (5 Mohs), did not differ significantly from Brand C. Although they have the same Mohs hardness for their abrasives, it is possible that the difference in their abrasivity is due to the varying size, shape, or concentration of their abrasive systems. ${ }^{15}$ Another probable reason for the high abrasiveness of Brand $\mathrm{X}$ is that it contains citric acid. The erosive property of citric acid may have a synergistic effect and contributes to the dissolution of the inorganic content of dentin, and thus, to its total abrasivity. 23,31

Studies have recommended the use of low abrasive toothpastes for cases of NCCLs ${ }^{12}$ and eroded dentin. ${ }^{13}$ Although not generalizable because of the low sample size, Brands $G, H$, and $H N$, having no significant difference from Brand C (RDA 68), may be used for such clinical situations. Brands X and U, being ranked lower than Brand $\mathrm{P}$ (RDA 150), and with RDA below the maximum safety limit of 250 , are clinically safe to use.

For future studies, we recommend a larger sample size for better validity of the results, use of at least a $0.5 \mu \mathrm{m}$ surface roughness for a smoother baseline for all samples, include positive controls with medium and very highly abrasive RDAs so that toothpastes may be better categorized, and analysis of abrasivity of other Philippine-brand toothpastes and their variants. We also recommend further study on: prevalence of NCCLs and dentin sensitivity in the Philippines, effect on abrasivity of other ingredients, e.g., citric acid and titanium dioxide. In the interest of public health transparency, we recommend that local manufacturers be required to make public and periodically update the RDA values of their toothpastes. 


\section{CONCLUSION}

Three toothpaste brands (Brands $\mathrm{G}, \mathrm{H}$, and $\mathrm{HN}$ ) can be considered as low abrasive toothpastes. Brand $\mathrm{X}$ can be considered as a high abrasive toothpaste. It is unclear as to which category is Brand U. Ranked in decreasing order of abrasivity: Brands $\mathrm{P}, \mathrm{X}, \mathrm{U}, \mathrm{H}, \mathrm{C}, \mathrm{HN}$, and $\mathrm{G}$.

\section{Acknowledgments}

The authors would like to acknowledge the UP College of Dentistry and 3M Philippines for the use of their facilities and as a study site, and to their staff for their invaluable assistance in the conduct of this research.

\section{Statement of Authorship}

Both authors participated in data collection and analysis, and approved the final version submitted.

\section{Authors Disclosure}

Both authors declared no conflicts of interest.

\section{Funding Source}

This study is personally funded by the authors.

\section{REFERENCES}

1. Antonson SA, Anusavice KJ. Materials and processes for cutting, grinding, finishing, and polishing. In: Anusavice KJ, Shen C, Rawls HR, eds. Phillips' Science of Dental Materials. 12th ed. St. Louis, Missouri: Elsevier Saunders. 2013. pp. 250-1.

2. Heymann HO, Swift, EJ Jr, Ritter AV. Sturdevant's Art and Science of Operative Dentistry. 6th Ed. St. Louis, Missouri: Elsevier/Mosby; 2013. pp. 11, 100,110,133, 134.

3. Dyer D, Addy M, Newcombe RG. Studies in vitro of abrasion by different manual toothbrush heads and a standard toothpaste. J Clin Periodontol. 2000; 27(2):99-103.

4. Lindhe J, Lang NP, Karring T, editors. Clinical Periodontology and Implant Dentistry. 5th Ed. Oxford, UK: Blackwell Munksgaard; 2008. pp. 396, 719.

5. Rath SK, Sharma V, Pratap CB, Chaturvedi TP. Abrasivity of dentifrices: an update. SRM J Res in Dent Sci. 2016; 7:96-100. doi: 10.4103/0976-433X.182662.

6. Arnold WH, Gröger C, Bizhang M, Naumova EA. Dentin abrasivity of various desensitizing toothpastes. Head Face Med. 2016; 12: 16-20. doi: 10.1186/s13005-016-0113-1.

7. Souza-Rodrigues RD, Ferreira SS, D'almeida-Couto RS, Lachowski KM, Sobral MA, Marques MM. Choice of toothpaste for the elderly: an in vitro study. Braz Oral Res. 2015; 29(1):1-7. doi: 10.1590/18073107BOR-2015.vol29.0094.

8. International Organization for Standardization (ISO). Dentistry - dentifrice - requirements, test methods and marking. 3rd ed. Switzerland: The Organization; 2017. 1-5 p. Reference number ISO 11609:2017(E).

9. American Dental Association [Internet]. Chicago: American Dental Association; Oral health topics: toothpastes; [cited: 2019 Aug 29] Available from: https://www.ada.org/en/member-center/oral-healthtopics/toothpastes

10. Hunter ML, Addy M, Pickles MJ, Joiner A. The role of toothpastes and toothbrushes in the aetiology of tooth wear. Int Dent J. 2002; 52(S5):399-405. doi: 10.1111/j.1875-595X.2002.tb00729.x.

11. Baig M. Understanding the role of tribology in maintaining oral hygiene [dissertation]. [Southampton]: University of Southampton; $2018.303 \mathrm{p}$.
12. Sabrah AH, Turssi CP, Lippert F, Eckert GJ, Kelly AB, Hara AT. 3D-Image analysis of the impact of toothpaste abrasivity on the progression of simulated non-carious cervical lesion. J Dent. 2018; 73:14-8. doi: 10.1016/j.jdent.2018.03.012

13. Wiegand A, Kuhn M, Sener B, Roos M, Attin T. Abrasion of eroded dentin caused by toothpaste slurries of different abrasivity and toothbrushes of different filament diameter. J Dent. 2009; 37(6): 480-4. doi: 10.1016/j.jdent.2009.03.005.

14. Vieira GH, Nogueira MB, Gaio EJ, Rosing CK, Santiago SL, Rego RO. Effect of whitening toothpastes on dentin abrasion: an in vitro study. Oral Health Prev Dent. 2016; 14(6):547-53. doi: 10.3290/ j.ohpd.a36465.

15. Johannsen G, Tellefsen G, Johannsen A, Liljeborg A. The importance of measuring toothpaste abrasivity in both quantitative and qualitative way. Acta Odontol Scand. 2013; 71(3-4):508-17. doi: 10.3109/00016357.2012.696693.

16. Iqbal K, Asmat M, Jawed S, Mushtaque A, Mohsin F, Hanif S, et al. Role of different ingredients of toothpastes and mouthwashes in oral health. J Pak Dent Assoc. 2011; 20(3):163-70.

17. Subramanian S, Appukuttan D, Tadepalli A, Gnana PP, Victor DJ. The role of abrasives in dentifrices. J Pharm Sci \& Res. 2017; 9(2),221-4.

18. Camargo IM, Saiki M, Vasconcellos MB, Avila DM. Abrasiveness evaluation of silica and calcium carbonate used in the production of dentifrices. J Cosmet Sci. 2001; 52(3):163-7.

19. De Boer P, Duinkerke AS, Arends J. Influence of tooth paste particle size and tooth brush stiffness on dentine abrasion in vitro. Caries Res. 1985; 19(3):232-9. doi: 10.1159/000260849.

20. Lippert F. An introduction to toothpaste - its purpose, history and ingredients. Monogr Oral Sci. 2013; 23:1-14. doi: 10.1159/000350456.

21. Marchetti L. Relative dentifrice abrasivity on dentin and enamel [master's thesis]. [Newark (NJ)]: New Jersey Institute of Technology; 1997. $974 \mathrm{p}$.

22. Moore C, Addy M. Wear of dentine in vitro by toothpaste abrasives and detergents alone and combined. J Clin Periodontol. 2005; 32(12): 1242-6. doi: 10.1111/j.1600-051X.2005.00857.x

23. Reis C, De-Deus G, Leal F, Azevedo E, Countinhi-Filho T, Piciornik S. Strong effect on dentin after the use of high concentrations of citric acid: an assessment with co-site optical microscopy and ESEM. Dent Mater. 2008; 24(12):1608-15. doi: 10.1016/j.dental.2008.03.027.

24. White DJ, Schneiderman E, Colón E, St. John S. A profilometrybased dentifrice abrasion method for V8 brushing machines. Part I: Introduction to RDA-PE. J Clin Dent. 2015; 26(1):1-6. PubMed PMID: 26054184.

25. Falla-Sotelo FO, Rizzutto MA, Tabacniks MH, Added N, Barbosa MDL, Markarian RA, et al. Analysis and discussion of trace elements in teeth of different animal species. Braz J Phys. 2005; 35(3b): 761-2. doi: 10.1590/S0103-97332005000500010.

26. Wegehaupt FJ, Widmer R, Attin T. Is bovine dentine an appropriate substitute in abrasion studies. Clin Oral Investig. 2009; 14(2):201-5. doi: 10.1007/s00784-009-0283-3.

27. Yassen GH, Platt JA, Hara AT. Bovine teeth as substitute for human teeth in dental research: a review of literature. J Oral Sci. 2011; 53(3):273-82. doi: 10.2334/josnusd.53.273.

28. Schemehorn BR, Moore MH, Putt MS. Abrasion, polishing, and stain removal characteristics of various commercial dentifrices in vitro. J Clin Dent. 2011; 22(1):11-8.

29. Nik TH, Hooshmand T, Farhadifard H. Effect of different types of toothpaste on the frictional resistance between orthodontic stainless steel brackets and wires. J Dent (Tehran). 2017; 14(5):275-81.

30. Milleman KR, Milleman JL, Young S, Parkinson C. Randomized controlled trial to explore the effect of experimental low abrasivity dentifrices on enamel gloss and smoothness, and the build-up of extrinsic tooth stain. J Clin Dent. 2017; 28(2):1-8.

31. Yu H, Wegehaupt FJ, Wiegand A, Roos M, Attin T, Buchalla W. Erosion and abrasion of tooth-colored restorative materials and human enamel. J Dent. 2009; 37(12):913-22. doi: 10.1016/j.jdent. 2009.07.006. 